\title{
Sensitivity of Magnetic Resonance Imaging in Evaluation of Patients with Hip Joint Pain
}

\author{
Akhita Singhania ${ }^{1}$ Rajasbala P. Dhande ${ }^{1}$ Suvarn Gupta ${ }^{2} \quad$ Shraddha Singhania ${ }^{1}$ Shashank Jain ${ }^{2}$ \\ ${ }^{1}$ Department of Radiodiagnosis, Jawaharlal Nehru Medical College, \\ Sawangi, Wardha, Maharashtra, India \\ 2Department of Orthopedics, Jawaharlal Nehru Medical College, \\ Sawangi, Wardha, Maharashtra, India \\ Address for correspondence Shraddha Singhania, DMRD, \\ Singhania House, Shivnagar, Wardha 442001, Maharashtra, India \\ (e-mail: shraddha2527@gmail.com).
}

\author{
Abstract \\ Keywords \\ - hip pain \\ - magnetic resonance \\ imaging \\ - pathologies \\ - avascular necrosis
}

Introduction Modern magnetic resonance imaging (MRI) has a great sensitivity in detecting hip joint abnormalities, and because of its property of excellent visualization of soft tissue and nonionizing radiation, it is the modality of choice these days in not only adults but also pediatric musculoskeletal pathologies.

Materials and Methods It was a prospective study performed in a tertiary care institute from 2016 to 2018. Total 64 cases with hip pathology attending orthopedics OPD (out patient department) and consenting to participate were included in the study. All the consenting participants were subjected to MRI scan.

Results The most common pathology detected was avascular necrosis consisting of 28 cases. The next most common abnormality detected was infective arthritis, found in seven cases. Three patients were diagnosed with metastasis.

Conclusion MRI is the diagnostic modality of choice for pathologies of hip for which radiographic and clinical findings are inconclusive. With MRI, one can stage the pathology to prognosticate and influence therapeutic decisions.

\section{Introduction}

The hip is a stable, major weight-bearing joint with significant mobility. Magnetic resonance imaging, with its development of techniques, particularly for the hip, has opened a new horizon regarding clinical approach to pathologies leading to hip joint pain. Modern MRI has a great sensitivity in detecting hip joint abnormalities, and because of its property of excellent visualization of soft tissue and nonionizing radiation, it is the modality of choice these days in not only adults but also pediatric musculoskeletal pathologies. ${ }^{1,2}$

Evaluation of the patient with hip pain is still a diagnostic dilemma for physicians. The differential diagnosis is diverse including common entities such as osteoarthritis, fracture, and avascular necrosis (AVN), as well as less common entities including pigmented villonodular synovitis, synovial osteochondromatosis, snapping hip syndrome, and hemorrhage into the ligamentum teres. ${ }^{3,4}$

With the use of dynamic contrast-enhanced MRI, abnormal femoral head perfusion (common complication associate with femoral neck fracture internal fixation) can be detected before the development of femoral head osteonecrosis, subchondral collapse, and secondary osteoarthritis. ${ }^{5}$

Despite the vast literature supporting the role of imaging of the hip with MRI, its role as a diagnostic imaging modality continues to evolve. This study emphasizes the role of MRI in the evaluation of hip joint pain.

\section{Material and Methods}

This prospective study was conducted on 64 patients with painful hip joint; males and females with age ranging between 10 and 70 years, referred to Department of Radiodiagnosis, for MRI from Department of Orthopaedics. The study period was from June 2016 to September 2018. Detailed history was taken of patients who then underwent local examination of the diseased hip. MRI of the hip joint was performed on all suspected patients sent to Department of Radiodiagnosis. Patients were followed up for final diagnosis that was done on the basis of X-ray correlation, laboratory
DOI https://doi.org/

10.1055/s-0039-1677784

ISSN 2455-7420.
License terms

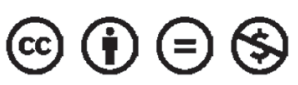


tests (complete blood count [CBC], erythrocyte sedimentation rate [ESR], liver function test [LFT], kidney function test [KFT], C-reactive protein [CRP], rheumatoid arthritis [RA] factor, human leukocyte antigen B27 [HLA B27], sickling, uric acid test, etc.) and clinical correlation.

Patients with congenital hip pathologies, with metallic implants and cardiac pacemakers, and postoperative patients were excluded from the study. Standard imaging protocol was used, and in patients with AVN of the femoral head, Ficat and Arlet staging system was used. ${ }^{6}$

\section{Results}

This study was conducted on 64 patients at a tertiary care institute. Age of patients ranged from 10 to 70 years. Maximum number of patients were in the age group of 21 to 30 years (27 cases-42\%). Male-to-female ratio was approximately 47:17. Affection was unilateral in 32 (50\%) cases, whereas it was bilateral in 29 (45.3\%) cases. Contrast agent was used whenever necessary to evaluate the extent of the disease and the pattern of involvement. Various pathologies detected on MRI are shown in - Table 1. The most common pathology encountered was AVN comprising 28 of the 64 cases. AVN was unilateral in 10 of the 28 cases and bilateral in 18 cases. In patients with AVN of the femoral head, the most common finding was double-line sign, seen in 23 (95\%) patients, which was followed by subchondral signal abnormality in 20 (83.3\%) patients, as depicted in - Table 2. Maximum patients had stage II AVN followed by stages III and I AVN, as shown in - Table 3.

The next most common abnormality detected was infective arthritis, found in 10 cases. It was mainly bacterial in origin in most cases. In infective arthritis of the hip, MRI helps particularly in detecting soft tissue lesions that are not well seen on other modalities. There are some features that support discrimination between tuberculous arthritis and pyogenic arthritis such as the presence of bone erosion and

Table 1 Various pathologies detected on MRI

\begin{tabular}{|l|l|}
\hline MRI findings & Total \\
\hline Avascular necrosis of femoral head & 28 \\
\hline Osteoarthritis & 5 \\
\hline Stress fracture & 2 \\
\hline Septic arthritis & 7 \\
\hline Tubercular arthritis & 3 \\
\hline Synovitis & 2 \\
\hline Metastasis & 3 \\
\hline Perthes' disease & 2 \\
\hline Tumors & 3 \\
\hline Inflammatory arthritis & 2 \\
\hline Osteomyelitis & 3 \\
\hline Sacroiliitis & 3 \\
\hline Migratory osteoporosis & 1 \\
\hline
\end{tabular}

Abbreviation: MRI, magnetic resonance imaging.
Table 2 MRI findings in patients with AVN of femoral head

\begin{tabular}{|l|l|l|}
\hline MRI findings & No of patients & Percentage (\%) \\
\hline $\begin{array}{l}\text { Subchondral signal } \\
\text { abnormality }\end{array}$ & 20 & 83.33 \\
\hline Double line sign & 23 & 95.83 \\
\hline Marrow edema & 16 & 66.67 \\
\hline Joint effusion & 5 & 20.83 \\
\hline Joint space narrowing & 12 & 50.00 \\
\hline
\end{tabular}

Abbreviations: AVN, avascular necrosis; MRI, magnetic resonance imaging.

Table 3 MRI staging of AVN

\begin{tabular}{|l|l|l|}
\hline Staging of AVN & No of patients $(n=28)$ & Percentage (\%) \\
\hline Stage I & 6 & 21.43 \\
\hline Stage II & 11 & 39.29 \\
\hline Stage III & 7 & 25.00 \\
\hline Stage IV & 4 & 14.29 \\
\hline Total & 28 & 100 \\
\hline
\end{tabular}

Abbreviations: AVN, avascular necrosis; MRI, magnetic resonance imaging.

absence of subchondral marrow signal intensity abnormality, favoring a diagnosis of tuberculous arthritis.

Two patients from the pediatric age group had Perthes' disease. In cases of Perthes' disease, there were marrow edema and contour abnormality with unilateral involvement. There was no bilateral joint involvement or effusion noted.

Three patients diagnosed with carcinoma of the breast/ colon/kidney demonstrated metastatic focus with MRI findings of postcontrast enhancement (100\%), hyperintensity in the adjacent bones (100\%), adjacent muscle involvement (66.67\%) with unilateral involvement in (66.67\%), and bilateral involvement in 33.3\% patients. Two cases of stress fractures were detected using MRI.

MRI was most sensitive in cases with stress fracture, synovitis, metastasis, Perthes' disease, sacroiliitis, and migratory osteoporosis, that is, $100 \%$ followed by AVN of the femoral head (85.7\%), osteoarthritis (80\%), septic arthritis (71.4\%), tumors (66.6\%), osteomyelitis (66.6\%), inflammatory arthritis (50\%), and least sensitive in patients with tubercular arthritis (33.3\%) (-Fig. 1).

\section{Discussion}

Our study comprised patients belonging to age groups between 11 and 70 years with mean \pm standard deviation (SD) of $36.40 \pm 14.80$ years. Maximum patients belonged to the age group between 21 and 30 years followed by 41 and 50 years, which is similar to study done by Ragab et al, ${ }^{7}$ Drar et al, ${ }^{8}$ and Tripathi et al. ${ }^{9}$ However, age does not have any significant role in determining the onset of hip pain. In our study, there was male preponderance, that is, out of 64 patients, 47 (73.44\%) were male and 17 (26.5\%) were female, which can be compared with study done by Ragab et $\mathrm{al}^{7}$ and Tripathi et $\mathrm{al}^{9}$ that 


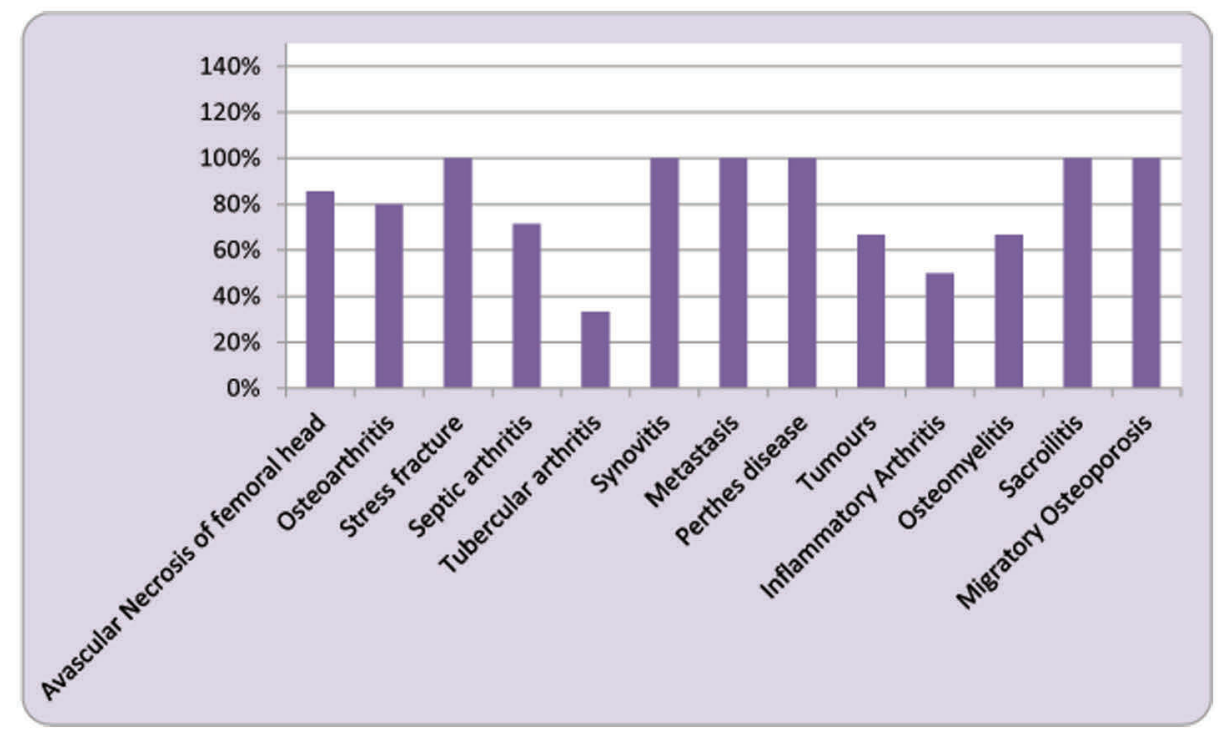

Fig. 1 Sensitivity of magnetic resonance imaging (MRI) in patients with hip pain.

also showed male predominance. However, in study done by Drar et al, ${ }^{8}$ female preponderance was seen. There were $50 \%$ patients with bilateral hip involvement and $45.3 \%$ patients with unilateral hip involvement, and $4.7 \%$ had sacroiliitis in our study, which was comparable with study by Tripathi et $\mathrm{al}^{9}$ that showed $48 \%$ bilateral hip involvement and $52 \%$ unilateral involvement.

According to our study, the most common MRI finding in AVN is double-line sign (95.83\%) that is similar to the finding by Ragab et $\mathrm{al}^{7}(100 \%)$; however, Drar et $\mathrm{al}^{8}$ and Tripathi et $\mathrm{al}^{9}$ have found subchondral signal abnormality to be more common. In our study, maximum AVN cases were detected in during stage II (39.29\%), which is similar to the finding by Beltran et $\mathrm{al}^{10}$ who in their study detected $62 \%$ cases in stage II of AVN. There were six (21.43\%) patients who came with hip joint pain whose X-ray was normal but on MRI was detected with stage I AVN. Our finding was supported with the findings by Beltran et $\mathrm{al}^{10}$ who found MRI signs of stage I AVN in $21.6 \%$ of hips with normal X-ray. Hence MRI is the most sensitive modality for early detection of AVN. Patients with sickle cell anemia usually presented in late stage of AVN, that is, stages III and IV, which is similar to the findings by Sartoris and Resnick ${ }^{11}$ and Coleman et al. ${ }^{12}$

Out of five patients, the most common finding in patients with osteoarthritis was marginal osteophytes (100\%), followed by joint space narrowing (80\%) and subchondral cyst (60\%), and others were joint effusion (20\%), marrow edema (20\%), and adjacent soft tissue edema (20\%). Boutry et al ${ }^{13}$ also reported most cases of marginal osteophytes (83\%). Ragab et $\mathrm{al}^{7}$ studied joint space narrowing in $78.1 \%$ cases of osteoarthritis, which was similar to our study.

In our study, there was only one case showing migratory osteoporosis in which marrow edema and joint effusion were observed in MRI, which was comparable to study by Drar et al, ${ }^{8}$ which reported marrow edema in $100 \%$ cases and joint effusion in $50 \%$ cases and study done by Ragab et $\mathrm{al}^{7}{ }^{7}$ in which marrow edema was present in $100 \%$ cases, but joint effusion was seen in $33.3 \%$ cases.

In seven patients with septic arthritis, the most significant MRI findings were marrow edema (100\%), synovial thickening (100\%), joint effusion (71.4\%), and bone destruction (71\%), and least common was involvement of adjacent muscles (57.14\%). These results were comparable to the study by Ragab et al, ${ }^{7}$ which showed marrow edema (100\%), synovial thickening (68.8\%), joint effusion (50\%), and bone destruction (62.5\%). Kwack et $\mathrm{al}^{14}$ reported synovial thickening (55.5\%), joint effusion (100\%), and marrow edema (33.3\%) as the characteristic findings in septic arthritis.

In three patients with tubercular arthritis, maximum patients had marrow edema (100\%), joint effusion (100\%), and involvement of adjacent muscle (100\%), and others had synovial thickening (33.3\%), and bone erosion (33.3\%). Similar findings were done in study of Ragab et al. ${ }^{7}$

Out of two patients with Perthes' disease, both had marrow edema (100\%) and contour abnormality (100\%) with unilateral involvement. There was no case of bilateral joint involvement. Drar et $\mathrm{al}^{8}$ also reported similar findings in their study; that is, $80 \%$ cases showed unilateral affection and contour abnormality and marrow edema was observed in maximum cases.

The most sensitive MRI finding in patients with stress fracture is marrow edema that was found in all patients with stress fracture. Our study is comparable with studies done by Ragab et $\mathrm{al}^{7}$ and Drar et $\mathrm{al}^{8}$ who reported similar findings. The second most common finding is subchondral linear hypointensity. Joint effusion was least found in any of the studies.

MRI is the modality of choice for early detection of inflammatory arthritis. The most sensitive feature in diagnosing rheumatoid arthritis is synovial thickening that we found in all our patients (100\%). Uneven and degree of synovial thickening also helps in distinguishing infective and 
inflammatory arthritis. Our study and finding are comparable those by Choi et al. ${ }^{15}$ The other most common MRI feature is bone erosion (100\%). There are studies by Narváez et al ${ }^{16}$ and Tehranzadeh et al ${ }^{17}$ in the literature, which have shown persistence and progression of bone erosions on MRI in cases of inflammatory arthritis.

We had three patients complaining of hip joint pain, who were previously diagnosed with carcinoma (CA) prostate (two patients) and CA stomach (one patient). In our study, the MRI finding comprised postcontrast enhancement and hyperintensity in the adjacent bones in all patients with adjacent muscle involvement in two patients. Two out of three patients had unilateral involvement and one had bilateral hip joint involvement. The MRI features in our study are similar to those explained in the literature such as Heindel et a ${ }^{18}$ and Yang et al. ${ }^{19}$

\section{Sensitivity of Magnetic Resonance Imaging in Patients with Hip Joint Pain}

We found that MRI is the modality of choice for early detection of AVN, even in stage I in which X-rays are normal. Our study is comparable with many studies in the literature like Stoica et al, ${ }^{20}$ Rupp et al, ${ }^{21}$ and Pierce et al. ${ }^{22}$ Accurate localization and knowledge of the extent of the necrosis by means of MRI make it possible to plan an osteotomy accurately.

We found MRI to be highly sensitive (80\%) in diagnosis of osteoarthritis of the hip joint. This was comparable with study done by Drar et $\mathrm{al}^{8}$ who found MRI sensitivity to be $80 \%$ in case of osteoarthritis of the hip joint. Boutry et $\mathrm{al}^{13}$ also discussed the widespread application MRI as a modality of choice for evaluation of painful hip joint due to rapidly destructive osteoarthritis of the hip joint.

MRI facilitates early diagnosis of stress fracture. In this study, two patients were diagnosed with stress fracture and MRI findings were true positive in both patients, hence making MRI $100 \%$ sensitive to cases of stress fracture, as the dominant finding in cases of stress fracture is bone marrow edema that is very well appreciated on STIR sequences. Our finding is comparable with those by Kiuru et $\mathrm{al}^{23}$ and Mammoto et al. ${ }^{24}$

Out of 64 patients, 7 were diagnosed with septic arthritis on MRI with 5 of them being true positive; hence, we found MRI to be $71.43 \%$ sensitive in cases of septic arthritis that is comparable with study by Kwack et a ${ }^{14}$ who found the sensitivity to be $82 \%$.

Three patients were diagnosed with tubercular arthritis on MRI; however, only one of them who had bone erosions and synovial thickening came out to be true positive. Hence the sensitivity of MRI for tubercular arthritis was 33.33\%. Concluding, the most sensitive MRI findings for diagnosis of tubercular arthritis are synovial thickening and bone erosions, which is also quoted by Ragab et al. ${ }^{7}$

The sensitivity for tumors and metastasis on MRI is high in our study, which is $100 \%$ in case of metastasis and $66.7 \%$ in case of bone tumor (two out of three patients were true positive) which comparable with study by Tripathi et a ${ }^{9}$ who also found similar results.
We found MRI to be $100 \%$ sensitive in cases of Perthes' disease that is contradicted by Tiwari et $\mathrm{a}^{25}$ who found low sensitivity and high specificity of MRI. However, our study is comparable with Drar et $\mathrm{al}^{8}$ who found MRI to be $80 \%$ sensitive in patients with Perthes' disease.

\section{Conclusion}

MRI has high sensitivity of $85.71 \%$ in patients with AVN of the femoral head. It also helps in early diagnosis of AVN stages, which prevents late complications. MRI has high sensitivity in patients with osteoarthritis, stress fracture, septic arthritis, metastasis, Perthes' disease, sacroiliitis, and migratory osteoporosis. On the basis of MRI findings, it is moderately sensitive in patients with tumor, inflammatory arthritis, and osteomyelitis. MRI was found to be least sensitive in patients with tubercular arthritis.

Hence, MRI is the modality of choice for characterization of the various disorders. It helps in assessing the entire extent of osseous, chondral, and soft tissue involvement in patients with hip pain. It can also accurately demonstrate marrow edema, joint effusions, synovial thickening, articular cartilage abnormalities, subchondral bone, ligaments, muscles, juxta-articular soft tissues, and adjacent bones.

\section{Conflict of Interest}

None.

\section{References}

1 Gardner-Medwin JM, Irwin G, Johnson K. MRI in juvenile idiopathic arthritis and juvenile dermatomyositis. Ann N Y Acad Sci 2009;1154(1):52-83

2 Andersson Gäre B. Juvenile arthritis-who gets it, where and when? A review of current data on incidence and prevalence. Clin Exp Rheumatol 1999;17(3):367-374

3 Fitzgerald RH Jr. Acetabular labrum tears. Diagnosis and treatment. Clin Orthop Relat Res 1995; (311):60-68

4 McCarthy JC, Busconi B. The role of hip arthroscopy in the diagnosis and treatment of hip disease. Orthopedics 1995;18(8):753-756

5 Berkowitz JL, Potter HG. Advanced MRI techniques for the hip joint: focus on the postoperative hip. AJR Am J Roentgenol 2017;209(3):534-543

6 Stoller D. Magnetic Resonance Imaging in Orthopaedics and Sports Medicine. 3rd ed. Philadelphia, PA: Wolters Kluwer; 2015:125-126

7 Ragab Y, Emad Y, Abou-Zeid A. Bone marrow edema syndromes of the hip: MRI features in different hip disorders. Clin Rheumatol 2008;27(4):475-482

8 Drar HAEAE, Mohammed BAED, Ali ZAEM. The role of MRI in the evaluation of painful hip joint (MRI of hip joint). International Journal of Medical Imaging 2014;2(3):77-82

9 Tripathi P, Singh S, Khantal N. Hip pathology findings on magnetic resonance imaging: a study from tertiary care institute. Int J Sci Stud 2016;4(3):35-38

10 Beltran J, Burk JM, Herman LJ, et al. Avascular necrosis of the femoral head: early MRI detection and radiological correlation. Magn Reson Imaging 1987;5(6):431-442

11 Sartoris DJ, Resnick D. MR imaging of the musculoskeletal system: current and future status. AJR Am J Roentgenol 1987; 149(3):457-467 
12 Coleman BG, Kressel HY, Dalinka MK, Scheibler ML, Burk DL, Cohen EK. Radiographically negative avascular necrosis: detection with MR imaging. Radiology 1988;168(2):525-528

13 Boutry N, Paul C, Leroy X, Fredoux D, Migaud H, Cotten A. Rapidly destructive osteoarthritis of the hip: MR imaging findings. AJR Am J Roentgenol 2002;179(3):657-663

14 Kwack KS, Cho JH, Lee JH, Cho JH, Oh KK, Kim SY. Septic arthritis versus transient synovitis of the hip: gadolinium-enhanced MRI finding of decreased perfusion at the femoral epiphysis. AJR Am J Roentgenol 2007;189(2):437-445

15 Choi JA, Koh SH, Hong SH, Koh YH, Choi JY, Kang HS. Rheumatoid arthritis and tuberculous arthritis: differentiating MRI features. AJR Am J Roentgenol 2009;193(5):1347-1353

16 Narváez JA, Narváez J, De Lama E, De Albert M. MR imaging of early rheumatoid arthritis. Radiographics 2010;30(1): 143-163, discussion 163-165

17 Tehranzadeh J, Ashikyan O, Dascalos J. Magnetic resonance imaging in early detection of rheumatoid arthritis. Semin Musculoskelet Radiol 2003;7(2):79-94

18 Heindel W, Gübitz R, Vieth V, Weckesser M, Schober O, Schäfers M. The diagnostic imaging of bone metastases. Dtsch Arztebl Int 2014;111(44):741-747

19 Yang HL, Liu T, Wang XM, Xu Y, Deng SM. Diagnosis of bone metastases: a meta-analysis comparing ${ }^{18}$ FDG PET, CT, MRI and bone scintigraphy. Eur Radiol 2011;21(12):2604-2617
20 Stoica Z, Dumitrescu D, Popescu M, Gheonea I, Gabor M, Bogdan N. Imaging of avascular necrosis of femoral head: familiar methods and newer trends. Curr Health Sci J 2009; 35(1):23-28

21 Rupp N, Reiser M, Hipp E, et al. [Diagnosis of bone necrosis by magnetic resonance tomography. The potentials for early diagnosis] [in German]. RoFo 1985;142(2):131-137

22 Pierce TP, Jauregui JJ, Cherian JJ, Elmallah RK, Mont MA. Imaging evaluation of patients with osteonecrosis of the femoral head. Curr Rev Musculoskelet Med 2015;8(3):221-227

23 Kiuru MJ, Pihlajamaki HK, Hietanen HJ, Ahovuo JA. MR imaging, bone scintigraphy, and radiography in bone stress injuries of the pelvis and the lower extremity. Acta Radiol 2002;43(2):207-212

24 Mammoto T, Hirano A, Tomaru Y, et al. High-resolution axial MR imaging of tibial stress injuries. Sports Med Arthrosc Rehabil Ther Technol 2012;4(1):16

25 Tiwari V, Gamanagatti S, Mittal R, Nag H, Khan SA. Correlation between MRI and hip arthroscopy in children with Legg-Calve-Perthes disease. Musculoskelet Surg 2018; 102(2):153-157 